\title{
An Innovative Algorithmic Approach for Solving Profit Maximization Problems
}

\author{
Abul Kalam Azad ${ }^{1}$, Mosharraf Hossain ${ }^{2}$ \\ ${ }^{1}$ Department of Mathematics, Rajshahi Government City College, Rajshahi, Bangladesh \\ ${ }^{2}$ Department of IPE, Rajshahi University of Engineering and Technology, Rajshahi, Bangladesh
}

Email address:

pgdmbamilton@yahoo.com (A. K. Azad), mosharraf.hossain@ruet.ac.bd (M. Hossain)

To cite this article:

Abul Kalam Azad, Mosharraf Hossain. An Innovative Algorithmic Approach for Solving Profit Maximization Problems. Mathematics Letters. Vol. 4, No. 1, 2018, pp. 1-5. doi: 10.11648/j.ml.20180401.11

Received: December 10, 2017; Accepted: December 25, 2017; Published: January 19, 2018

\begin{abstract}
The new algorithmic technique developed in this article to solve the profit maximization problems using transportation algorithm of Transportation Problem (TP) has three basic parts; first converting the maximization problem into the minimization problem, second formatting the Total Opportunity Table (TOT) from the converted Transportation Table (TT), and last allocations of profits using the Row Average Total Opportunity Value (RATOV) and Column Average Total Opportunity Value (CATOV). The current algorithm considers the average of the cell values of the TOT along each row identified as RATOV and the average of the cell values of the TOT along each column identified as CATOV. Allocations of profits are started in the cell along the row or column which has the highest RATOVs or CATOVs. The Initial Basic Feasible Solution (IBFS) obtained by the current method is better than some other familiar methods which is discussed in this paper with the three different sized examples.
\end{abstract}

Keywords: TP, TT, TOT, RATOV, CATOV, IBFS

\section{Introduction}

Transportation problems in linear programming show the mathematical optimal ways to get the solutions of transportation problems. Transportation algorithm is an effective tool to get optimal profit. Some of the usual algorithms to solve the transportation problems are North West Corner (NWC) Method, Matrix Minima Method, and Vogel's Approximation Method (VAM). Afterwards many researchers provide many helpful algorithms to get IBFS of transportation problems. Some of the methods and algorithms that the current work has gone through are: P. Pandian and G. Natarajan's 'A New Approach for Solving Transportation Problems with Mixed Constraints' [1]; 'An Innovative Method for Solving Transportation Problem' [2] by N. M. Deshmukh; 'Modified Vogel's Approximation Method for Unbalance Transportation Problem' [3] by N. Balakrishnan; Serder Korukoglu and Serkan Balli's 'An Improved Vogel's Approximation Method (IVAM) for the Transportation Problem' [4]; Harvey H. Shore's 'The Transportation Problem and the Vogel's Approximation
Method' [5]; 'A modification of Vogel's Approximation Method through the use of Heuristics' [6] by D. G. Shimshak, J. A. Kaslik and T. D. Barelay; A. R. Khan's 'A Re-solution of the Transportation Problem: An Algorithmic Approach' [7]; 'A new approach for finding an Optimal Solution for Transportation Problems' by V. J. Sudhakar, N. Arunnsankar, and T. Karpagam [8]; Kirca and Satir's 'A Heuristic for Obtaining an Initial Solution for the Transportation Problem' [9]. Md. Amirul Islam et al. [10] calculate the Difference Indicators by taking the difference of the largest and the next largest cell value of each row and each column of the TOT for the allocation of units of the TT to determine maximum profit. The above mentioned algorithms cited in this article are beneficial to find the IBFS to solve profit maximization objective. The current research also ads a useful algorithm which gives a better IBFS in the profit maximization problems.

\section{Algorithm}

The developed algorithm in the current work involves three parts: 
1. Converting the maximization problem into the minimization problem

Conversion of the problem
2. Algorithm for Total Opportunity Table (TOT)

3. Algorithm for allocation

Subtract the highest profit from the other profits in the TT and place the subtracted values in a new a TT. In this way the maximization problem becomes the minimization problem.

\section{Algorithm for TOT}

Step 1

Subtract the smallest entry from each of the elements of every row of the new TT and place them on the right-top of corresponding elements.

Step 2 Apply the same operation on each of the columns and place them on the right-bottom of the corresponding elements.

Step 3 Form the TOT whose entries are the summation of right-top and right-bottom elements of Steps 1 and 2.

\section{Algorithm for Allocation}

Place the average of total opportunity values of cells of the TOT in the right side along each row in the first

Step 1 bracket identified as Row Average Total Opportunity Value (RATOV) and the average of total opportunity values of cells in the below along each column in the first bracket identified as Column Average Total Opportunity Value (CATOV).

Identify the highest element among the RATOVs and CATOVs, if there are two or more highest elements; choose

Step 2 the highest element along which the smallest valued element is present. If there are two or more smallest elements, choose any one of them arbitrarily.

Step 3 Allocate $x_{i j}=\min \left(a_{i}, b_{j}\right)$ on the left top of the smallest entry in the $(i, j)$ th of the TT.

If $a_{i}<b_{j}$, leave the ith row and readjust $b_{j}$ as $b_{j}^{\prime}=b_{j}-a_{i}$.

Step 4 If $a_{i}>b_{j}$, leave the jth column and readjust $a_{i}$ as $a_{i}^{\prime}=a_{i}-b_{j}$.

If $a_{i}=b_{j}$, leave either ith row or $\mathrm{j}$-th column but not both.

Step 5 Repeat Steps 1 to 4 until the rim requirement satisfied.

Step 6 Calculate $p=\sum_{i=1}^{m} \sum_{j=1}^{n} p_{i j} x_{i j}, P$ being the maximum profit where $p_{i j}$ is the profit unit of $\mathrm{i}$-th row and $\mathrm{j}$-th column of the TT corresponding to the basic cells of TOT.

\section{Numerical Examples}

Example 01

Three products $\mathrm{P}_{1}, \mathrm{P}_{2}$, and $\mathrm{P}_{3}$ are produced in three machines $\mathrm{M}_{1}, \mathrm{M}_{2}$, and $\mathrm{M}_{3}$ and their profit margins are given in the following table.

Table 1. Tabular Form of the Problem.

\begin{tabular}{lllll}
\hline \multirow{2}{*}{ Machines } & \multicolumn{2}{l}{ Products } & \multirow{2}{*}{ Capacity $\left(\boldsymbol{a}_{\boldsymbol{i}}\right)$} \\
\cline { 2 - 5 } $\mathbf{P}_{\mathbf{1}}$ & $\mathbf{P}_{\mathbf{2}}$ & $\mathbf{P}_{\mathbf{3}}$ & \\
$\mathrm{M}_{1}$ & 290 & 280 & 300 & 200 \\
$\mathrm{M}_{2}$ & 250 & 270 & 230 & 200 \\
$\mathrm{M}_{3}$ & 350 & 370 & 380 & 200 \\
Demand $\left(b_{j}\right)$ & 150 & 300 & 150 & 600 \\
\hline
\end{tabular}

We want to maximize the profit by the current algorithm. Solution

We subtract the maximum profit 380 from other profits of the TT.

Table 2. Minimizing the Problem.

\begin{tabular}{lllll}
\hline \multirow{2}{*}{ Machines } & \multicolumn{2}{l}{ Products } & \multirow{2}{*}{$\left(\boldsymbol{a}_{\boldsymbol{i}}\right)$} \\
\cline { 2 - 4 } & $\mathbf{P}_{\mathbf{1}}$ & $\mathbf{P}_{\mathbf{2}}$ & $\mathbf{P}_{\mathbf{3}}$ & \\
\hline $\mathrm{M}_{1}$ & 90 & 100 & 80 & 200 \\
$\mathrm{M}_{2}$ & 130 & 110 & 150 & 200 \\
\hline
\end{tabular}

\begin{tabular}{lllll}
\hline \multirow{2}{*}{ Machines } & Products & & & $\left(\boldsymbol{a}_{\boldsymbol{i}}\right)$ \\
\cline { 2 - 5 } & $\mathbf{P}_{\mathbf{1}}$ & $\mathbf{P}_{\mathbf{2}}$ & $\mathbf{P}_{\mathbf{3}}$ & 200 \\
$\mathrm{M}_{3}$ & 30 & 10 & 0 & 600 \\
$\left(b_{j}\right)$ & 150 & 300 & 150 & 6 \\
\hline
\end{tabular}

The row differences and column differences from the lowest row and the lowest column are:

Table 3. Row-Column Difference Table.

\begin{tabular}{lllll}
\hline Machines & Products & & & $\left(\boldsymbol{a}_{\boldsymbol{i}}\right)$ \\
\cline { 2 - 4 } & $\mathbf{P}_{\mathbf{1}}$ & $\mathbf{P}_{\mathbf{2}}$ & $\mathbf{P}_{\mathbf{3}}$ & 200 \\
$\mathrm{M}_{1}$ & $90_{60}^{10}$ & $100_{90}^{20}$ & $80_{80}^{0}$ & 200 \\
$\mathrm{M}_{2}$ & $130_{100}^{20}$ & $110_{100}^{0}$ & $150_{150}^{40}$ & 200 \\
$\mathrm{M}_{3}$ & $30_{0}^{30}$ & $10_{0}^{10}$ & $00_{0}^{0}$ & 200 \\
$\left(b_{j}\right)$ & 150 & 300 & 150 & 600 \\
\hline
\end{tabular}

The TOT is:

Table 4. Total Opportunity Table.

\begin{tabular}{|c|c|c|c|c|}
\hline \multirow{2}{*}{ Machines } & \multicolumn{3}{|c|}{ Products } & \multirow{2}{*}{$\left(a_{i}\right)$} \\
\hline & $\mathbf{P}_{1}$ & $\mathbf{P}_{2}$ & $\mathbf{P}_{3}$ & \\
\hline $\mathrm{M}_{1}$ & 70 & 110 & 80 & 200 \\
\hline $\mathrm{M}_{2}$ & 120 & 100 & 190 & 200 \\
\hline $\mathrm{M}_{3}$ & 30 & 10 & 0 & 200 \\
\hline$\left(b_{j}\right)$ & 150 & 300 & 150 & 600 \\
\hline
\end{tabular}


The allocations with the help of RATOVs and CATOVs are:

Table 5. Allocations in TOT.

\begin{tabular}{lllll}
\hline \multirow{2}{*}{ Machines } & \multicolumn{2}{l}{ Products } & $\mathbf{P}_{\mathbf{3}}$ & \\
\cline { 2 - 4 } & $\mathbf{P}_{\mathbf{1}}$ & $\mathbf{P}_{\mathbf{2}}$ & $\mathbf{P}_{\mathbf{3}}$ & 200 \\
$\mathrm{M}_{1}$ & ${ }^{150} 70$ & 110 & ${ }^{50} 80$ & 200 \\
$\mathrm{M}_{2}$ & 120 & ${ }^{200} 100$ & 190 & 200 \\
$\mathrm{M}_{3}$ & 30 & ${ }^{100} 10$ & ${ }^{100} 0$ & 600 \\
$\left(b_{j}\right)$ & 150 & 300 & 150 & \\
& 73.3 & 73.3 & 90 & \\
CATOV & 50 & 60 & 40 & \\
& - & 60 & 40 & \\
RATOV & 86.6 & 86.6 & 95 & \\
& 136.6 & - & - & \\
\hline
\end{tabular}

The allocations in the original TT are:

Table 6. Allocations in the Original Problem.

\begin{tabular}{lllll}
\hline \multirow{2}{*}{ Machines } & Products & & \multirow{2}{*}{$\left(\boldsymbol{a}_{\boldsymbol{i}}\right)$} \\
\cline { 2 - 4 } & $\mathbf{P}_{\mathbf{1}}$ & $\mathbf{P}_{\mathbf{2}}$ & $\mathbf{P}_{\mathbf{3}}$ & 200 \\
\hline $\mathrm{M}_{1}$ & ${ }^{150} 290$ & 280 & ${ }^{50} 300$ & 200 \\
$\mathrm{M}_{2}$ & 250 & ${ }^{200} 270$ & 230 & 200 \\
$\mathrm{M}_{3}$ & 350 & ${ }^{100} 370$ & ${ }^{100} 380$ & 600 \\
$\left(b_{j}\right)$ & 150 & 300 & 150 & \\
\hline
\end{tabular}

The maximum profit is $P=\sum_{i=1}^{m} \sum_{j=1}^{n} p_{i j} x_{i j}$

$=290 \times 150+300 \times 50+270 \times 200+370 \times 100+380 \times 100$

$=187500$

Example 02

Three products $\mathrm{P}_{1}, \mathrm{P}_{2}$, and $\mathrm{P}_{3}$ are produced in four machines $\mathrm{M}_{1}, \mathrm{M}_{2}, \mathrm{M}_{3}$, and $\mathrm{M}_{4}$, and their profit margins are given in the following table.

Table 7. Tabular Form of the Problem.

\begin{tabular}{lllll}
\hline \multirow{2}{*}{ Machines } & \multicolumn{3}{l}{ Products } & Capacity $\left(\boldsymbol{a}_{\boldsymbol{i}}\right)$ \\
\cline { 2 - 5 } & $\mathbf{P}_{\mathbf{1}}$ & $\mathbf{P}_{\mathbf{2}}$ & $\mathbf{P}_{\mathbf{3}}$ & \\
\hline $\mathrm{M}_{1}$ & 10 & 15 & 12 & 50 \\
$\mathrm{M}_{2}$ & 6 & 9 & 20 & 30 \\
$\mathrm{M}_{3}$ & 21 & 13 & 7 & 20 \\
$\mathrm{M}_{4}$ & 23 & 2 & 25 & 60 \\
Demand $\left(b_{j}\right)$ & 80 & 70 & 10 & 160 \\
\hline
\end{tabular}

We want to maximize the profit by the current algorithm.

Solution

We subtract the maximum profit 25 from other profits of the TT.

Table 8. Minimizing the Problem.

\begin{tabular}{lllll}
\hline \multirow{2}{*}{ Machines } & Products & & & \multirow{2}{*}{$\left(\boldsymbol{a}_{\boldsymbol{i}}\right)$} \\
\cline { 2 - 4 } & $\mathbf{P}_{\mathbf{1}}$ & $\mathbf{P}_{\mathbf{2}}$ & $\mathbf{P}_{\mathbf{3}}$ & \\
\hline $\mathrm{M}_{1}$ & 15 & 10 & 13 & 50 \\
$\mathrm{M}_{2}$ & 19 & 16 & 5 & 30 \\
$\mathrm{M}_{3}$ & 4 & 12 & 18 & 20 \\
$\mathrm{M}_{4}$ & 2 & 23 & 0 & 60 \\
$\left(b_{j}\right)$ & 80 & 70 & 10 & 160 \\
\hline
\end{tabular}

The row differences and column differences from the lowest row and the lowest column are:
Table 9. Row-Column Difference Table.

\begin{tabular}{|c|c|c|c|c|}
\hline \multirow{2}{*}{ Machines } & \multicolumn{3}{|c|}{ Products } & \multirow{2}{*}{$\left(a_{i}\right)$} \\
\hline & $\mathbf{P}_{1}$ & $\mathbf{P}_{2}$ & $\mathbf{P}_{3}$ & \\
\hline $\mathrm{M}_{1}$ & $15_{13}^{5}$ & $10_{0}^{0}$ & $13 \frac{3}{13}$ & 50 \\
\hline $\mathrm{M}_{2}$ & $19_{17}^{14}$ & $16_{6}^{11}$ & $5 \frac{0}{5}$ & 30 \\
\hline $\mathrm{M}_{3}$ & $4 \stackrel{0}{2}$ & $12 \stackrel{8}{2}$ & $18_{18}^{14}$ & 20 \\
\hline $\mathrm{M}_{4}$ & $2_{0}^{2}$ & 223 & $0_{0}^{0}$ & 60 \\
\hline$\left(b_{j}\right)$ & 80 & 70 & 10 & 160 \\
\hline
\end{tabular}

The TOT is:

Table 10. Total Opportunity Table.

\begin{tabular}{lllll}
\hline \multirow{2}{*}{ Machines } & Products & & & \multirow{2}{*}{$\left(\boldsymbol{a}_{\boldsymbol{i}}\right)$} \\
\cline { 2 - 4 } & $\mathbf{P}_{\mathbf{1}}$ & $\mathbf{P}_{\mathbf{2}}$ & $\mathbf{P}_{\mathbf{3}}$ & 50 \\
$\mathrm{M}_{1}$ & 18 & 0 & 16 & 30 \\
$\mathrm{M}_{2}$ & 31 & 17 & 5 & 20 \\
$\mathrm{M}_{3}$ & 2 & 10 & 32 & 60 \\
$\mathrm{M}_{4}$ & 2 & 36 & 0 & 160 \\
$\left(b_{j}\right)$ & 80 & 70 & 10 & \\
\hline
\end{tabular}

The allocations with the help of RATOVs and CATOVs are:

Table 11. Allocations in TOT.

\begin{tabular}{lllll}
\hline \multirow{2}{*}{ Machines } & Products & & & \multirow{2}{*}{$\left(\boldsymbol{a}_{\boldsymbol{i}}\right)$} \\
\cline { 2 - 4 } & $\mathbf{P}_{\mathbf{1}}$ & $\mathbf{P}_{\mathbf{2}}$ & $\mathbf{P}_{\mathbf{3}}$ & 50 \\
$\mathrm{M}_{1}$ & 18 & ${ }^{50} 0$ & 16 & 30 \\
$\mathrm{M}_{2}$ & 31 & ${ }^{20} 17$ & ${ }^{10} 5$ & 20 \\
$\mathrm{M}_{3}$ & ${ }^{20} 2$ & 10 & 32 & 60 \\
$\mathrm{M}_{4}$ & ${ }^{60} 2$ & 36 & 0 & 160 \\
$\left(b_{j}\right)$ & 80 & 70 & 10 & \\
& 13.2 & 15.7 & 13.2 & \\
CATOV & 13.2 & 15.7 & - & \\
& 7.3 & 15.3 & - & \\
& 10 & 5 & - & - \\
RATOV & 11.3 & 9 & 9 & 6 \\
& 17.6 & 24 & - & - \\
\hline
\end{tabular}

The allocations in the original TT are:

Table 12. Allocations in the Original Problem.

\begin{tabular}{lllll}
\hline \multirow{2}{*}{ Machines } & Products & & \multirow{2}{*}{$\left(\boldsymbol{a}_{\boldsymbol{i}}\right)$} \\
\cline { 2 - 4 } & $\mathbf{P}_{\mathbf{1}}$ & $\mathbf{P}_{\mathbf{2}}$ & $\mathbf{P}_{\mathbf{3}}$ & 50 \\
\hline $\mathrm{M}_{1}$ & 10 & ${ }^{50} 15$ & 12 & 30 \\
$\mathrm{M}_{2}$ & 6 & ${ }^{20} 9$ & ${ }^{10} 20$ & 20 \\
$\mathrm{M}_{3}$ & ${ }^{20} 21$ & 13 & 7 & 60 \\
$\mathrm{M}_{4}$ & ${ }^{60} 23$ & 2 & 25 & 160 \\
$\left(b_{j}\right)$ & 80 & 70 & 10 & \\
\hline
\end{tabular}

The maximum profit is $P=\sum_{i=1}^{m} \sum_{j=1}^{n} p_{i j} x_{i j}$

$=15 \times 50+9 \times 20+20 \times 10+21 \times 20+23 \times 60$

$=2930$

Example 03

Four products $\mathrm{P}_{1}, \mathrm{P}_{2}, \mathrm{P}_{3}$, and $\mathrm{P}_{4}$ are produced in three machines $\mathrm{M}_{1}, \mathrm{M}_{2}$, and $\mathrm{M}_{3}$ and their profit margins are given in the following table. 
Table 13. Tabular Form of the Problem.

\begin{tabular}{llllll}
\hline \multirow{2}{*}{ Machines } & \multicolumn{2}{l}{ Products } & \multicolumn{2}{c}{ Capacity } \\
\cline { 2 - 5 } & $\mathbf{P}_{\mathbf{1}}$ & $\mathbf{P}_{\mathbf{2}}$ & $\mathbf{P}_{\mathbf{3}}$ & $\mathbf{P}_{\mathbf{4}}$ & $\left(\boldsymbol{a}_{\boldsymbol{i}}\right)$ \\
\hline $\mathrm{M}_{1}$ & 4 & 5 & 6 & 7 & 10 \\
$\mathrm{M}_{2}$ & 7 & 5 & 6 & 8 & 13 \\
$\mathrm{M}_{3}$ & 8 & 6 & 5 & 5 & 17 \\
Demand $\left(b_{j}\right)$ & 9 & 13 & 8 & 10 & 40 \\
\hline
\end{tabular}

We want to maximize the profit by the current algorithm.

Solution

We subtract the maximum profit 8 from other profits of the TT.

Table 14. Minimizing the Problem.

\begin{tabular}{llllll}
\hline \multirow{2}{*}{ Machines } & \multicolumn{2}{l}{ Products } & & $\mathbf{P}_{\mathbf{4}}$ & $\left(\boldsymbol{a}_{\boldsymbol{i}}\right)$ \\
\cline { 2 - 5 } & $\mathbf{P}_{\mathbf{1}}$ & $\mathbf{P}_{\mathbf{2}}$ & 2 & 1 & 10 \\
\hline $\mathrm{M}_{1}$ & 4 & 3 & 2 & 0 & 13 \\
$\mathrm{M}_{2}$ & 1 & 3 & 3 & 3 & 17 \\
$\mathrm{M}_{3}$ & 0 & 2 & 8 & 10 & 40 \\
$\left(b_{j}\right)$ & 9 & 13 & & \\
\hline
\end{tabular}

The row differences and column differences from the lowest row and the lowest column are:

Table 15. Row-Column Difference Table.

\begin{tabular}{|c|c|c|c|c|c|}
\hline \multirow{2}{*}{ Machines } & \multicolumn{4}{|c|}{ Products } & \multirow{2}{*}{$\left(a_{i}\right)$} \\
\hline & $\mathbf{P}_{1}$ & $\mathbf{P}_{2}$ & $\mathbf{P}_{3}$ & $\mathbf{P}_{4}$ & \\
\hline $\mathrm{M}_{1}$ & $4 \frac{3}{4}$ & $3 \frac{2}{1}$ & $2 \stackrel{1}{0}$ & $1_{1}^{0}$ & 10 \\
\hline $\mathrm{M}_{2}$ & $1_{1}^{1}$ & $3_{1}^{3}$ & $2_{0}^{2}$ & $0_{0}^{0}$ & 13 \\
\hline $\mathrm{M}_{3}$ & $0_{0}^{0}$ & $2_{0}^{2}$ & $3_{1}^{3}$ & $3 \frac{3}{3}$ & 17 \\
\hline$\left(b_{j}\right)$ & 9 & 13 & 8 & 10 & 40 \\
\hline
\end{tabular}

The TOT is:

Table 16. Total Opportunity Table.

\begin{tabular}{llllll}
\hline \multirow{2}{*}{ Machines } & Products & & & & \multirow{2}{*}{$\left(\boldsymbol{a}_{\boldsymbol{i}}\right)$} \\
\cline { 2 - 5 } & $\mathbf{P}_{\mathbf{1}}$ & $\mathbf{P}_{\mathbf{2}}$ & $\mathbf{P}_{\mathbf{3}}$ & $\mathbf{P}_{\mathbf{4}}$ & \\
\hline $\mathrm{M}_{1}$ & 7 & 3 & 1 & 1 & 10 \\
$\mathrm{M}_{2}$ & 2 & 4 & 2 & 0 & 13 \\
$\mathrm{M}_{3}$ & 0 & 2 & 4 & 6 & 17 \\
$\left(b_{j}\right)$ & 9 & 13 & 8 & 10 & 40 \\
\hline
\end{tabular}

The allocations with the help of RATOVs and CATOVs are:

Table 17. Allocations in TOT.

\begin{tabular}{llllll}
\hline \multirow{2}{*}{ Machines } & Products & & & & \multirow{2}{*}{$\left(\boldsymbol{a}_{\boldsymbol{i}}\right)$} \\
\cline { 2 - 5 } & $\mathbf{P}_{\mathbf{1}}$ & $\mathbf{P}_{\mathbf{2}}$ & $\mathbf{P}_{\mathbf{3}}$ & $\mathbf{P}_{\mathbf{4}}$ & 10 \\
\hline $\mathrm{M}_{1}$ & 7 & ${ }^{5} 3$ & ${ }^{5} 1$ & 1 & 10 \\
$\mathrm{M}_{2}$ & 2 & 4 & ${ }^{3} 2$ & ${ }^{10} 0$ & 13 \\
$\mathrm{M}_{3}$ & 90 & ${ }^{8} 2$ & 4 & 6 & 17 \\
$\left(_{b_{j}}\right)$ & 9 & 13 & 8 & 10 & 40 \\
& 3 & 3 & 2.3 & 2.3 & \\
CATOV & - & 3 & 2.3 & 2.3 & \\
& - & 3.5 & 1.5 & 0.5 & \\
RATOV & - & - & 1.5 & 0.5 & \\
& 3 & 1.6 & 1.6 & 1 & \\
& 2 & 2 & 2 & 1 & \\
\hline
\end{tabular}

The allocations in the original TT are:

Table 18. Allocations in the Original Problem.

\begin{tabular}{llllll}
\hline \multirow{2}{*}{ Machines } & Products & & & $\left(\boldsymbol{a}_{\boldsymbol{i}}\right)$ \\
\cline { 2 - 5 } & $\mathbf{P}_{\mathbf{1}}$ & $\mathbf{P}_{\mathbf{2}}$ & $\mathbf{P}_{\mathbf{3}}$ & $\mathbf{P}_{\mathbf{4}}$ & \\
\hline $\mathrm{M}_{1}$ & 4 & ${ }^{5}$ & ${ }^{5} 6$ & 7 & 10 \\
$\mathrm{M}_{2}$ & 7 & 5 & ${ }^{3} 6$ & ${ }^{10} 8$ & 13 \\
$\mathrm{M}_{3}$ & ${ }^{9} 8$ & ${ }^{8} 6$ & 5 & 5 & 17 \\
$\left(b_{j}\right)$ & 9 & 13 & 8 & 10 & 40 \\
\hline
\end{tabular}

The maximum profit is $P=\sum_{i=1}^{m} \sum_{j=1}^{n} p_{i j} x_{i j}$

$=5 \times 5+6 \times 5+6 \times 3+8 \times 10+8 \times 9+6 \times 8$

$=273$

\section{Comparison of Results}

The current algorithm mentioned in the article gives optimal or near optimal profit. However, a comparison of the developed work with the three existing conventional methods is presented in case of the three above examples.

Table 19. Assessment of the Developed Algorithm.

\begin{tabular}{llll}
\hline \multirow{2}{*}{ Methods } & Solutions & \\
\cline { 2 - 4 } & Example-1 & Example-2 & Example-3 \\
\hline Current Method & 187500 & 2930 & 273 \\
North-West Corner Method & 187000 & 1290 & 192 \\
Matrix Minima Method & 187000 & 2810 & 273 \\
VAM & 185500 & 2930 & 273 \\
Optimal Solution & 187500 & 2930 & 273 \\
\hline
\end{tabular}

\section{Conclusion}

The developed method considers all the opportunities of the cell values of the TOT by taking averages of the cell values. On the other hand, some other methods take some of the cell values only (ie. the lowest and the next lowest, the highest and the lowest etc.). The results or outcomes of the present algorithm are optimal or near optimal solutions while several examples were tested.

\section{References}

[1] P. Pandian and G. Natarajan, 'A New Approach for Solving Transportation Problems with Mixed Constraints', Journal of Physical Sciences, Vol. 14, 2010, 53-61, 2010.

[2] N. M. Deshmukh, 'An Innovative Method for Solving Transportation Problem', International Journal of Physics and Mathematical Sciences ISSN: 2277-2111 (Online), 2012.

[3] N. Balakrishnan, 'Modified Vogel's Approximation Method for Unbalance Transportation Problem,' Applied Mathematics Letters 3(2), 9,11,1990.

[4] Serdar Korukoglu and Serkan Balli, 'An Improved Vogel's Approximation Method for the Transportation Problem', Association for Scientific Research, Mathematical and Computational Application Vol. 16 No. 2, 370-381, 2011. 
[5] H. H. Shore, 'The Transportation Problem and the Vogel's Approximation Method', Decision Science 1(3-4), 441-457, 1970.

[6] D. G. Shimshak, J. A. Kaslik and T. D. Barelay, 'A modification of Vogel's Approximation Method through the use of Heuristics', Infor 19,259-263, 1981.

[7] Aminur Rahman Khan, 'A Re-solution of the Transportation Problem: An Algorithmic Approach' Jahangirnagar University Journal of Science, Vol. 34, No. 2, 49-62, 2011.

[8] V. J. Sudhakar, N. Arunnsankar, T. Karpagam, 'A new approach for find an Optimal Solution for Trasportation Problems', European Journal of Scientific Research 68 254$257,2012$.

[9] O. Kirca and A. Satir, 'A Heuristic for Obtaining an Initial Solution for the Transportation Problem', Journal of Operational Research Society, Vol. 41, No. 9, pp. 865-871, 1990.

[10] Md. Amirul Islam et al., 'Profit Maximization of a Manufacturing Company: An Algorithmic Approach', J. J. Math. and Math. Sci., Vol. 28, 29-37, 2013. 